2. Fair Work Commission. General Retail Industry Award 2010. Canberra: Fair Work Commission. www.fwc.gov.au/documents/documents/modern awards/award/ma000004/default.htm [cited 2015 May 5]

3. Australian Bureau of Statistics. 6302.0 - Average weekly earnings, Australia, 2014

http://www.abs.gov.au/ausstats/abs@.nsf/mf/6302.0 [cited 2015 May 5]

\section{Conflict of interest in medical journals}

I would like to thank John Dowden for summarising this important issue so well in his editorial (Aust Prescr 2015;38:2-3). Simply reporting a conflict of interest is pointless because it does not seem to change the interpretation or impact of the information presented. Clinical practice is largely determined by opinion leaders. With respect to publishing restrictions, this is the group we need to target, particularly because of their financial conflicts which are the most concerning.

These people write the most influential literature such as reviews, editorials, meta-analyses,

guidelines and position statements. A contemporary example is the literature around the efficacy of stroke thrombolysis, which has polarised clinicians worldwide. This controversy is complicated by the fact that virtually all the interpretative literature supporting the therapy has been written by people with financial conflicts.

What we need is a policy that prohibits the involvement of authors with financial conflicts in these interpretative types of articles. This is achievable, and in the long run will discourage clinicians from accepting money from industry for fear of limiting their academic careers.

\section{Chris Johnstone}

\section{Director, Emergency Medicine}

Caboolture Hospital, QId

Yes, readers are informed when a conflict of interest is declared. But no reader knows how to adjust the take-home messages from such articles to compensate for possible bias.' Declaring a conflict of interest shifts the responsibility of dealing with potential bias from the writer, through the editor, to the reader. Is this fair?

The author asks how hard will it be to find nonconflicted authors in Australia. Do we need someone who has done the primary research when any cardiologist with information-literacy skills could evaluate new antihypertensive drugs? In the age of evidence-based medicine, writing these articles is mostly literature reviewing. For opinion-based parts of an article, why is the opinion of someone less deeply involved less valuable than one likely to be influenced inappropriately?

You don't need to refuse to deal with people with a conflict of interest. Could you get a nonconflicted author to write the article, then ask your conflicted reviewer to edit it and give the final say to the writer? Or you could get the conflicted author to write the complicated physiology part, and another author to write the diagnostic or therapeutic sections?

No, we shouldn't be concerned about authors funded by the National Health and Medical Research Council (NHMRC) because the aim of NHMRC aligns with doctors' duty of care to their patients. In contrast, profit-seeking drug makers' primary obligations are to their shareholders. If those don't align with patients' interests we have a problem.

Lastly, is Australian Prescriber complicit if doctors are flouting the medical board requirement to not accept gifts of more than trivial value, ${ }^{2}$ when authors report funding from drug makers for conference attendances?

Peter Grant

Retired health professional

\section{REFERENCES}

1. Cain DM, Loewenstein G, Moore DA. The dirt on coming clean: perverse effects of disclosing conflicts of interest. J Legal Studies 2005;34:1-25.

2. Medical Board of Australia. Code of conduct. 2015. www.medicalboard.gov.au/Codes-Guidelines-Policies/ Code-of-conduct.aspx [cited 2015 May 5]

We read a very good editorial on conflict of interest by John Dowden, but we find that it deserves comment. We think that all authors who submit a manuscript of any type should disclose their financial and personal relationships that might bias or be perceived to bias an article's content. Therefore, when the editor of a journal writes an editorial, he also should report the conflict of interest, like some used to do.' The editorial board should vote to approve the editorial without participation of the editor. However, if an editorial focuses on therapeutics, other treatments or potential advice for medical practice, the editorial should be reviewed by external referees who report no conflict of interest. This is in addition to the author declaring any conflict of interests. ${ }^{2}$ Thus, when the editor is the author, they should also disclose their conflict of interest, as all other authors, ${ }^{3}$ for editorials that will be published in the journal.

Editors should not publish other types of articles such as research or review papers in their own 
journal. Perhaps the editor may publish information related to the journal or historic articles in the journal, provided it is peer-reviewed. However, the situation of editing and publishing in small and developing countries often makes the peerreview process difficult due to various restraints. Fortunately, Australia is not this type of country.

\section{Liljana Sokolova \\ Hygiene specialist \\ Institute of Public Health \\ Sombor, Serbia}

Rajko Igić

Pharmacologist and physiologist

John Stroger Hospital of Cook County

Chicago, Illinois

Rajko Igić accepted travel and local living expenses while Editor-in-Chief of the Scripta Medica, Banja Luka (2010 to 2013).

\section{REFERENCES}

1. Ferris LE, Fletcher RH. Conflict of interest in peerreviewed medical journals: the World Association of Medical Editors position on a challenging problem. J Young Pharm 2010;2:113-5.

2. International Committee of Medical Journal Editors. Conflicts of interest. 2015 www.icmje.org/conflicts-of-interest [cited 2015 May 5]

3. World Association of Medical Editors. Conflict of interest in peer-reviewed medical journals; 2009. www.wame.org/about/conflict-of-interest-in-peerreviewed-medical [cited 2015 May 5]

While I believe that we should be on guard against the promotional activities of the drug companies, I often wonder if we might be throwing the baby out with the bathwater. I do believe that many of the past developments in health care have been assisted by close association with the providers of our therapeutic armamentarium. Examples include the early association with a good apothecary, the development of the syringe, right up to lan Frazer and the human papillomavirus vaccine, and Fiona Woods and spray-on skin.

The practice of denying all access to industry is rather akin to the army introducing a new assault rifle without talking to the soldiers about their requirements or gaining feedback on its problems after its introduction. It has been suggested that generic manufacturers have added fuel to this discussion as they do not develop new drugs or technologies and therefore have no need to educate the users or hear their feedback.

What John Dowden and others, who may occasionally suckle at the government teat, consistently fail to mention is how devastating it would be to their career or their position on a government panel if they were to spout a line of doctrine that was diametrically opposed to the government or their academic institution. I have never seen mention of this in any article. Surely the loss of income from not towing the line is just as persuasive as a plate of soggy salad sandwiches? For example in the February 2015 issue of Medical Journal of Australia, an article concluded that cancer patients achieved better outcomes if they were treated in a major cancer institute.? The contact details for that author showed that his employment was at a major cancer institute. Are academics so beyond reproach that they don't feel the need to at least state the obvious?

I welcome continued discussion on the issue of the pervasive influence of company marketing on medical decision making, but I feel that a little perspective on this issue is warranted.

Peter McLaren

Anaesthetist

Southport, Qld

Peter McLaren hosts clinical meetings that may have industry-sponsored catering.

\section{REFERENCES}

1. Currow DC, Aranda S. Cancer control is not beyond us ... but could be if we don't invest wisely. Med J Aust 2015;202:63.

John Dowden, the Editor of Australian Prescriber and the author of the editorial, comments:

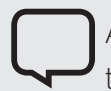

All of the new drug comments and most of the articles published in Australian Prescriber are written by authors without financial conflicts of interest. While some authors may declare such conflicts, the Editorial Executive Committee believes that the journal's editorial processes reduce the risk of bias. We have confidence in those processes and believe it is not unreasonable for readers to be able to make their own assessments. This is why it is important to publish any relevant conflicts of interest that have been declared.

The response of readers to conflicts of interest has been studied. A randomised trial involving BMJ readers found that their views of an article were more sceptical if conflicts of interest were declared.' As Dr Grant suggests, readers are more concerned if the author of the article is an employee of a company, rather than the recipient of a research grant. ${ }^{2}$

Professor Igić, Dr Sokolova and Dr McLaren raise the question of whether an author's employment should 


\section{<ustralian Prescriber}

VOLUME 38 : NUMBER 3 : JUNE 2015

be declared as a conflict of interest. Our Editorial Executive Committee will consider this, but it would mean duplicating the author's details given at the start of every article.

The authors of articles in Australian Prescriber do not have to be involved in primary research, but sometimes those who have participated in clinical trials know more about the problems of a new drug than the published literature might reveal. As Dr Johnstone points out, opinion leaders are influential and they can be used by the pharmaceutical industry for promotional purposes. ${ }^{3}$

The industry is moving towards greater transparency regarding the payments made to health professionals. ${ }^{4}$ Once this information is available, perhaps it will help the Medical Board of Australia to define what constitutes 'trivial value'.

\section{REFERENCES}

1. Chaudhry S, Schroter S, Smith R, Morris J. Does declaration of competing interests affect readers' perceptions? A randomised trial. BMJ 2002;325:1391-2.

2. Schroter S, Morris J, Chaudhry S, Smith R, Barratt H. Does the type of competing interest statement affect readers perceptions of the credibility of research? Randomised trial. BMJ 2004;328:742-3.

3 Flicker $\mathrm{L}$. The influence of opinion leaders. Aust Prescr 2012;35:74-5

4. Medicines Australia. Code of Conduct: Transparency reporting.

https://medicinesaustralia.com.au/code-of-conduct/ education-events-reports/ [cited 2015 May 5]

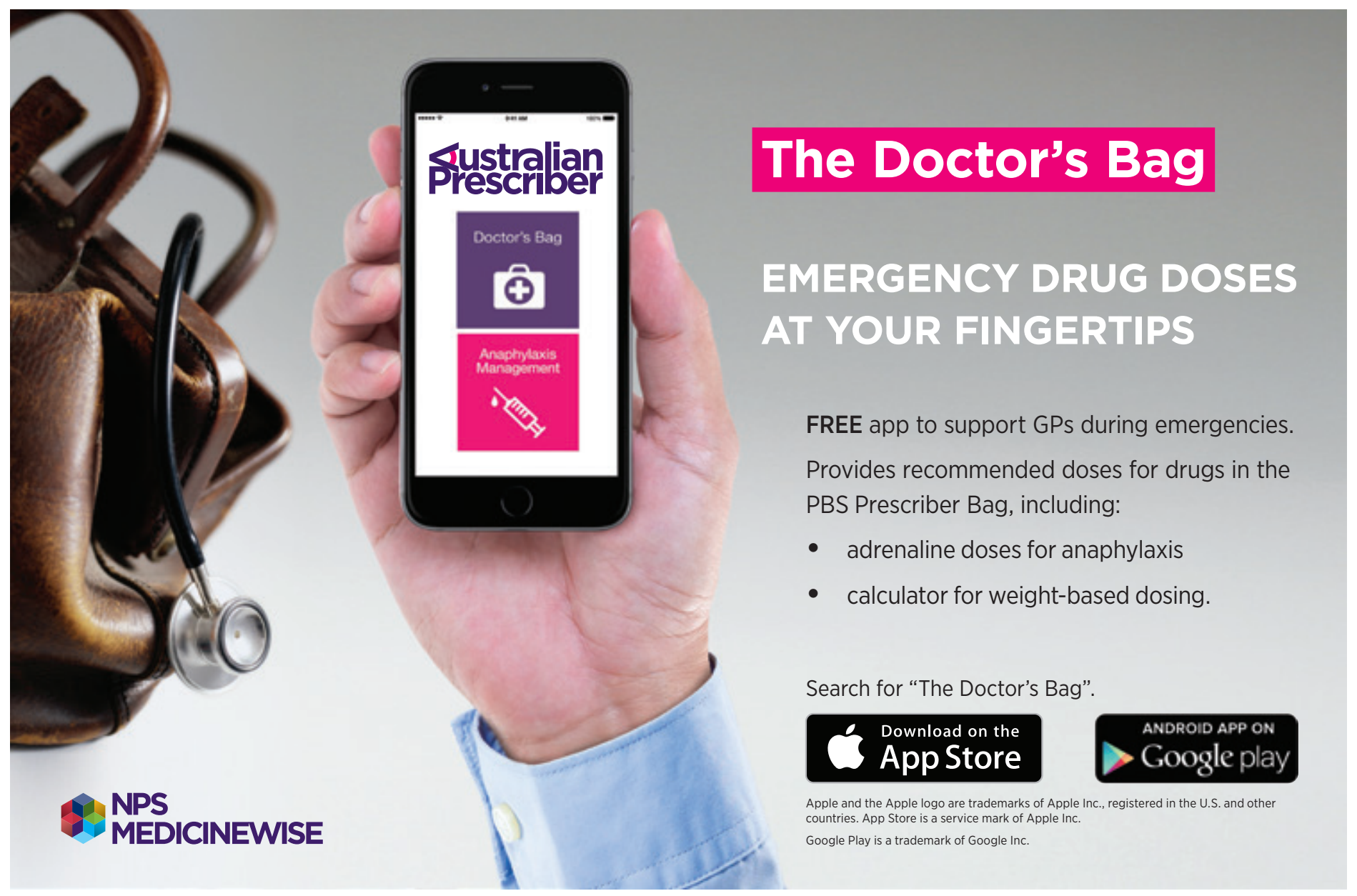

